\title{
BMJ Open Health, drugs and service use among deprived single men: comparing (subgroups) of single male welfare recipients against employed single men in Amsterdam
}

\author{
Tjerk C Kamann, ${ }^{1}$ Matty A S de Wit, ${ }^{2}$ Stephan Cremer, ${ }^{2}$ Aartjan T F Beekman ${ }^{3}$
}

To cite: Kamann TC, de Wit MAS, Cremer S, et al. Health, drugs and service use among deprived single men: comparing (subgroups) of single male welfare recipients against employed single men in Amsterdam. BMJ Open 2014;4:e004247. doi:10.1136/bmjopen-2013004247

- Prepublication history and additional material for this paper is available online. To view these files please visit the journal online (http://dx.doi.org/10.1136/ bmjopen-2013-004247).

Received 14 October 2013 Revised 23 January 2014 Accepted 24 January 2014

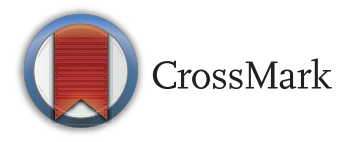

For numbered affiliations see end of article.

Correspondence to

Tjerk C Kamann;

tkamann@ggd.amsterdam.nl

\section{ABSTRACT}

Objectives: To aid public health policy in preventing severe social exclusion (like homelessness) and promoting social inclusion (like labour market participation), we aimed to quantify (unmet) health needs of an expectedly vulnerable population on which little was known about: single male welfare recipients (SIMwelfare). One of the main policy questions was: is there need to promote access to healthcare for this specific group?

Design: A cross-sectional study incorporating peer-topeer methodology to approach and survey SIM-welfare. Sociodemographics, prevalence of ill health, harmful drug use and healthcare utilisation for subgroups of SIMwelfare assessed with a different distance to the labour market and exposed to different reintegration policy were described and compared against single employed men (SIM-work).

Setting: Men between the age of 23 and 64, living in single person households in Amsterdam.

Participants: A random and representative sample of 472 SIM-welfare was surveyed during 2009-2010. A reference sample of 212 SIM-work was taken from the 2008 Amsterdam Health Survey.

Outcome measures: Standardised instruments were used to assess self-reported ill somatic and mental health, harmful drug use and service use.

Results: SIM-welfare are mostly long-term jobless, low educated, older men; $70 \%$ are excluded from reemployment policy due to multiple personal barriers. Health: $50 \%$ anxiety and depression; $47 \%$ harmful drug use; $41 \%$ multiple somatic illnesses. Health differences compared with SIM-work: (1) controlled for background characteristics, SIM-welfare report more mental (OR 4.0; $95 \% \mathrm{Cl} 2.1$ to 4.7 ) and somatic illnesses (OR 3.1; 95\% CI 2.7 to 6.0); (2) SIM-welfare assessed with the largest distance to the labour market report most combined health problems. Controlled for ill health, SIM-welfare are more likely to have service contacts than SIM-work.

Conclusions: SIM-welfare form a selection of men with disadvantaged human capital and health. Findings do not support a need to improve access to healthcare. The stratification of welfare clients distinguishes between health needs.

\section{Strengths and limitations of this study}

- By applying methodology of peer interviewers, this is the first study to draw epidemiological results from a seemingly representative sample of single male welfare recipients that authors are aware of.

- By combining standardised health indicators and drug use indicators with registration data concerning distance to the labour market, the study adds to few studies in which a vocational and public health perspective are served for the longterm jobless.

- Lack of diagnostic information about the nature and severity of illnesses and lack of more specific information about use of healthcare services make us careful in interpreting findings that participants more often have healthcare contacts than working single men, controlled for health differences.

\section{INTRODUCTION}

In this study, we aim to describe some demographics and quantify (unmet) health needs for an expectedly vulnerable population that has remained below the epidemiological radar: single male welfare recipients (SIMwelfare). With this information, we aim to assist public (health) policy in preventing severe social exclusion (like homelessness) and promoting social inclusion (like labour market participation).

\section{Why target single men on welfare?}

Within every society, there is a group of people who are not able to sufficiently access and mobilise personal and social resources to meet life's necessities. For some reason, especially single men are over-represented among the most severely excluded individuals of society. 
Homelessness, for instance, is a form of severe material deprivation associated with higher mortality rates, adverse health outcomes and substance abuse. ${ }^{1-5}$ In cities throughout Europe and other Organisation for Economic Cooperation and Development (OECD) countries, most homeless rough sleepers are single men (SIM), in the middle age range, with addictions and other health problems. ${ }^{6}$ The dominance of this profile among the homeless can be considered "one of the strongest comparative findings on homelessness in Europe that exists." Also in the Netherlands, with accessible healthcare and relatively high expenditure on social security, ${ }^{8}$ individuals falling through social safety nets are mostly SIM. In the four largest Dutch cities, $90 \%$ of the homeless are men, mostly single. ${ }^{9}$

These most marginalised people like the homeless and severe drug addicts are targeted as client groups for (individual) Public Mental Healthcare (PMHC). Clients receiving individual $\mathrm{PMHC}$ are typically homeless, drug addicted and/or suffering from severe mental disorders, but more broadly, individual PMHC is aimed at individuals who are in an unacceptable health condition and social situation, from a healthcare's perspective, but who, for whatever reason, fail to access private (regular) care and support to meet these needs by themselves and therefore need outreaching, often integrated care. In Amsterdam, between 2006 and 2011, SIM represented $80 \%$ of clients receiving integrated PMHC. ${ }^{10}$

PMHC does not operate merely at the individual level. At a risk group level, PMHC-services are concerned with the prevention of psychosocial deterioration in specific subgroups subject to risk-factors such as long-term unemployment, social isolation and psychiatric disorders. ${ }^{11}$ In this study, single jobless men residing in the last safety net of Dutch social security are put forward as a specific subgroup where such risk factors are expected to accumulate: SIM-welfare.

Before stating our research questions, we first (1) describe some common characteristics of SIM-welfare and then (2) distinguish between subgroups of SIM-welfare exposed to a different policy context.

\section{Characteristics of the target group}

In the Netherlands, all citizens who do not manage to provide themselves with sufficient income are eligible for income support. In Amsterdam, like in the rest of the Netherlands, one-third of working age welfare recipients are men living in single-person households. ${ }^{12}$ In January 2009, this group totalled 10270 SIM in Amsterdam. ${ }^{12}$ Common characteristics of SIM-welfare we study are (1) running a single person household—they all have a roof over their head and live there alone; (2) being dependent on welfare benefits set at around $70 \%$ of minimum wages-they belong to the poorest people in the Netherlands; (3) having no paid job-they might miss out immaterial benefits of performing a job like the time structure, status and social contacts ${ }^{13} 14$ and, perhaps most importantly, (4) SIM-welfare are all registered at and in contact with the municipal agency responsible for providing welfare services in Amsterdam (the municipal service for work and income (SWI)): SIM-welfare can be found and targeted for specific interventions.

\section{Policy context: subgroups}

Within the population of SIM-welfare, subgroups can be distinguished that are (1) exposed to different reintegration policy and (2) probably have different health needs.

From a public health perspective and a vocational welfare-to-work perspective, finding re-employment can be considered a desired rehabilitation outcome. ${ }^{15}{ }^{16}$ To cater for the diversity in reintegration needs among the heterogeneous population of welfare clients, SWI assesses clients 'distance to the labour market' based on clients' demographics, human capital indicators, health problems and other personal barriers hindering re-employment. Based on the assessment, clients are positioned on a 'stairway to work' ranging from step 1 (largest distance to labour market) to step 4 (smallest distance to the labour market). Clients on different steps are shown to differ in employability ${ }^{17}$ and are exposed to different reintegration policies (see table 1 for a description).

To aid prevention of psychosocial deterioration, unfavoured dropout from society and its costly remedy-integrated PMHC-between 2009 and 2012, a cohort study was set up to assess the needs among the hypothesised risk group of SIM-welfare. In the present manuscript, first results from this study at baseline are presented.

\section{Finding place?}

We aim to put this group on the epidemiological map by describing sociodemographics, prevalence of ill health, harmful drug use and healthcare use. These prevalences are useful for welfare-to-work-policy, public health policy and other studies in need of hard to reach reference groups.

\section{Disadvantaged health?}

From common characteristics of SIM-welfare, we can hypothesise health disadvantages. The association between unemployment and ill health is well established in the scientific literature. Owing to combined mechanisms of health selection (disadvantaged health restricts labour market participation and increases risk of job loss) and social causation (exposure to involuntary joblessness and its material and immaterial disadvantages have a negative effect on health), we expect a selection of SIM with disadvantaged human capital, health and addiction problems. ${ }^{18-21}$ We test whether, indeed, SIM-welfare have disadvantaged health and harmful drug use compared with single employed men (SIM-work). 
Table 1 'Stairway to work' model used by the municipal service for work and income in Amsterdam to re-integrate clients from welfare-towards-work

\begin{tabular}{|c|c|c|c|}
\hline Step 1. 'Care' & Step 2. 'Social Activation' & Step 3. 'Employment activation' & $\begin{array}{l}\text { Step 4. 'Employment } \\
\text { placement' }\end{array}$ \\
\hline $\begin{array}{l}\text { Personal barriers like } \\
\text { illness and addiction } \\
\text { need attention first, } \\
\text { before climbing the } \\
\text { stairway. } \\
\text { Clients have no } \\
\text { obligation to participate } \\
\text { in society or engage in } \\
\text { job-search activities. } \\
\text { Linkages to healthcare } \\
\text { through referral. }\end{array}$ & $\begin{array}{l}\text { Personal barriers prohibit } \\
\text { exposure to employment } \\
\text { activation. } \\
\text { Clients are obliged to } \\
\text { participate in low-threshold } \\
\text { social activation } \\
\text { programmes that suit } \\
\text { individual needs. }\end{array}$ & $\begin{array}{l}\text { Personal barriers prohibit placement } \\
\text { on labour market. } \\
\text { Clients are obliged to participate in } \\
\text { activation programmes to learn } \\
\text { basic employment skills (coming in } \\
\text { time, accepting directives), } \\
\text { orientation on labour market, } \\
\text { specific vocational training and } \\
\text { education. }\end{array}$ & $\begin{array}{l}\text { Clients are available to the } \\
\text { labour market. } \\
\text { Clients are obliged to show } \\
\text { sufficient effort in job search } \\
\text { activities. } \\
\text { If needed, support is offered } \\
\text { to enhance job search skills } \\
\text { and specific vocational } \\
\text { training. }\end{array}$ \\
\hline
\end{tabular}

\section{Disadvantaged service use?}

Improving access to healthcare for groups underutilising health services could prevent psychosocial deterioration and a possible need for costly outreaching individual PMHC at a later stage. In this study, we look to find evidence for relative under-utilisation of health services (ie, disadvantaged service use) among SIM-welfare by comparing their unmet health needs against SIM-work.

\section{Useful subgroups?}

We examine whether subgroups of SIM-welfare (1) assessed with a different distance to the labour market and (2) exposed to different reintegration policy also differ in (unmet) health needs. If so, this classification might also be useful for a differentiation in public health interventions. Also, it provides us with insight, as to what specific health needs are more and less associated with distance to the labour market, as assessed by SWI.

\section{Objectives}

1. Describe (subgroups of) SIM-welfare in terms of sociodemographics, prevalence of ill health, drugs misuse and healthcare use.

2. Analyse risk for ill health and harmful drug use for (subgroups of) SIM-welfare compared with SIM-work (controlled for sociodemographic background variables).

3. Analyse risk for service use for (subgroups of) SIM-welfare compared with SIM-work (controlled for sociodemographic background variables and relevant health needs).

\section{METHOD}

\section{Research as a reintegration programme}

The current study holds elements of participatory action research. Collaboration was developed between the Public Health Service (PHS), SWI and a private company specialised in empowerment of long-term jobless people. Together these partners set up a social activation programme aimed at (1) activating participants a step closer towards the labour market and (2) improving our research by recruiting a total of 50 SIM on welfare from SWI to take part in the research as advisors and 'peer' interviewers. One of the main tasks for participants was to approach and collect survey data from a random sample of other SIM on welfare: 'peers'.

To safeguard the quality of data collected, in $133 \mathrm{~h}$ sessions, participants were activated and trained in performing structured interviews. Teams of two were formed to conduct the interviews, so men with language or other problems that could hamper the quality of the survey could also participate with help of their 'buddy'. Interviews were recorded and based on these recordings, feedback was given to improve quality.

\section{Study sample and procedures}

In January 2009, a sample frame was created from the registration of SWI containing 9200 non-institutionalised men, between the age of 23 and 65, receiving welfare benefits for single person households, living in a house (1403 men who were registered as homeless/received integrated care were excluded), and for whom the distance to the labour market was registered.

The 9200 clients included in our sample frame were randomly numbered and subsequently approached in different rounds. Table 2 shows results from the approach.

After 10 months of fieldwork (July 2009 to May 2010), peer interviewers had personally interviewed 415 respondents. Respondents still not reached were reapproached by professional non-peer interviewers in October-December 2010. In the end, 472 of 1800 randomly sampled eligible clients were successfully interviewed (26\%).

\section{Reference data}

Reference data for SIM-work in the general population of Amsterdam $(n=294)$ were derived from the 
Table 2 Results of fieldwork (July 2009-December 2010)

\begin{tabular}{|c|c|c|}
\hline & $\mathbf{N}$ & Per cent \\
\hline Non-response before personal approach by peers & 596 & 33 \\
\hline Excluded from sample: no longer receiving welfare benefits & 170 & 9 \\
\hline Refused transfer of personal contact information from social services to the public health service & 426 & 24 \\
\hline Non-response after personal approach by peers & 732 & 41 \\
\hline Refused interview & 494 & 27 \\
\hline Not reached after at least 20 calls and 6 different house visits at different times and days of the week & 193 & 11 \\
\hline $\begin{array}{l}\text { Other: deceased, institutionalised, unable to conduct interview due to disease or language problems, } \\
\text { wrong contact information }\end{array}$ & 48 & 3 \\
\hline Response & 472 & 26 \\
\hline Interviewed by trained peers & 415 & 23 \\
\hline Interviewed by professional interviewers & 57 & 3 \\
\hline Total & 1800 & 100 \\
\hline
\end{tabular}

Amsterdam health survey of $2008 .^{22}$ A questionnaire was sent to a random sample of Amsterdam inhabitants stratified by (1) age and (2) prioritised deprivation areas. The Amsterdam monitor was based on a random sample of 13600 adults from the municipal population register, stratified by borough and age, who were invited by mail to complete a written or digital questionnaire in Dutch or Turkish language. Extensive effort was made to urge citizens of minority groups to respond to the survey: non-responders received follow-up letters, phone calls and house visits and were offered personal help to fill in the questionnaire. The overall response was $50 \%$, with higher response rates in women, elder persons, native Dutch citizens and residents of deprived neighbourhoods. Specifically, for SIM, aged 25-64, the response rate was $28 \%$.

Men living in a single person household $(n=463)$ aged 23-64 years were selected from the survey, and individual weights were calculated based on the distribution of age group $\times$ deprivation area as registered $^{23}$ for the total population of SIM in Amsterdam ( $\mathrm{N}=72$ 751). SIM reporting to work $>12 \mathrm{~h} /$ week were selected from the sample $(n=294)$.

\section{Measures}

For mental illness, the 10-item Kessler Psychological Distress Scale $(\mathrm{K} 10)^{24}$ was used to screen for common mental disorders (anxiety and depression) using a cut-off point of $\geq 20 .^{2526}$ On five-point Likert-type scales, individuals indicate the degree to which symptoms of psychological distress are present (1, none of the time; 5 , all of the time). With the chosen cut-off point of $\geq 20$ on the aggregate scale, the Dutch version of the K10 was shown to reach a sensitivity of 0.80 and a specificity of 0.81 for any depressive and/or anxiety disorder as assessed with the Composite International Diagnostic Interview. $^{27}$

For somatic illness, a standard questionnaire of the Dutch population health monitors was used. A list of 18 common chronic somatic illnesses was presented to participants (high blood pressure, diabetes, arthritis, cancer, stroke, etc). The number of self-reported medically diagnosed somatic illnesses was counted and dichotomised at a cut-off count of $\geq 2$.

For harmful drug use, we incorporated five indicators: (1) harmful drinking: alcohol consumption that is actually or potentially related to current social and medical problems is commonly measured with the Alcohol Use Disorders Identification Test (AUDIT). ${ }^{28}$ With a cut-off score of $\geq 8$, the AUDIT is shown to provide good sensitivity and specificity in the detection of current social and medical problems related to alcohol ${ }^{29} ;$ (2) daily cannabis use and (3) recent substance abuse. use of heroin, crack, coke, methadone or $\gamma$-hydroxybutyric acid, in the past 30 days. Self-reported addiction to alcohol, cannabis or other drugs was taken into account with respective indicators. If (4) respondents scored positive on any of the three mentioned measures of harmful drug use, they scored positive on the summery measure of harmful drug use. The only indicator of harmful drug use comparable with the reference sample is (5) excessive drinking, defined as, on average, drinking $>21$ alcoholic beverages per week.

The indicator for multiproblems was set at two or more of the following three indicators: mental illness, somatic illness and excessive drinking.

To measure service use, a standard list in Dutch population health monitors was used to assess whether or not the respondents had contact with the general practitioner, mental health, specialist care and addiction care in the past 12 months. Having no contact with healthcare in the past 12 months was calculated over a larger variety of possible healthcare contacts including contact with social care, a dentist, dietician, physiotherapist, speech therapist and receiving home care.

SIM-welfare's current position on SWI's stairway to work (1, largest distance to labour market; 4, smallest distance to labour market) was collected from the SWI registry when creating the sample frame (January 2009).

Migration history was divided into two categories: (1) ethnic Dutch: man and his parents are born in the Netherlands; (0) first-generation or second-generation 
migrant: man and/or parents are born outside of the Netherlands.

Low educational level refers to self-reported completed education below the level of senior general secondary, preuniversity or senior secondary vocational education. According to Dutch standards, in accordance with European Union (EU) norms, this implies having insufficient qualification for accessing the labour market.

\section{Analysis}

In all analyses, a $\mathrm{p}$ Value $<0.05$ is considered statistically significant.

When comparing characteristics between (subgroups of) SIM-welfare and SIM-work, without controlling for differences in background variables, calculated weights were applied to the stratified sample of SIM-work. Significance of found differences between samples were corrected for the design effect caused by weights. ${ }^{30}$ When testing for disadvantaged health and drugs misuse of (subgroups of) SIM-welfare compared with SIM-work, binary logistic regression analyses were performed in which background variables were entered as control variables. When testing for disadvantaged health service utilisation of (subgroups of) SIM-welfare compared with SIM-work, binary logistic regression analyses were performed, in which differences in specific service use (for instance mental healthcare) were controlled for differences in relevant health needs (for instance mental illness) and background variables.

\section{RESULTS}

\section{Representative sample?}

Non-response analysis showed no significant differences in level of education, distance to the labour market, duration of welfare dependence and frequency of contacts with social services between the response and nonresponse group. The distributions of all these variables closely resemble the 'true' distributions as registered for the research population (ie, the sample frame; $n=9200$ ). Only for age, we find a significant over-representation of older men in the response group. Older men between the age of 55 and 64 were slightly over-represented, and men between 23 and 35 years were slightly underrepresented in the response sample. See online supplementary table A1 for detailed information concerning the non-response.

\section{Composition of the target group}

SIM-welfare are distributed over SWI's stairway to work as follows: step 1, 37\%; step 2, 32\%; step 3, 28\%; step 4, $3 \%$. Steps 3 and 4 are merged in the analyses because of the small size of step $4(n=15)$.

Table 3 provides descriptives for and comparisons between (subgroups of) SIM-welfare and SIM-work. Prevalence of somatic and mental illness and service utilisation is higher among SIM-welfare than among SIM-work. SIM-welfare in subgroups assessed with a larger distance to the labour market generally show higher prevalence of illness, harmful drug use and service use. Also, differences in background variables are found between subgroups.

\section{Disadvantaged health?}

Controlled for differences in age, deprivation area, low education and migration history, table 4 shows a significantly higher risk of ill mental health, somatic illness and multiproblems for the total group of SIM-welfare and each of the subgroups compared against SIM-work. The difference is insignificant for the percentage of excessive drinkers and largest for the proportion of ill mental health.

Except for excessive drinking, risks generally increase for subgroups assessed with an increasing distance to the labour market, that is, subgroups on lower steps of SWI's stairway to work. This increase in risk is especially incremental for multiproblems. For somatic illness, the highest risk is observed in subgroup 1. For mental illness, similarly high risk is observed in subgroups 1 and 2 .

\section{Disadvantaged service use?}

It is shown that, controlled for differences on sociodemographic background variables, SIM-welfare are more likely than SIM-work to have contact with addiction care (controlled for excessive drinking), mental healthcare (controlled for mental illness) and specialist care (controlled for somatic illness; table 5).

Comparing between subgroups of SIM-welfare, further distance to labour market is related to higher odds of service use for mental and specialist somatic care (controlled for relevant health needs).

\section{DISCUSSION}

The primary objective in this study was to put the expectedly vulnerable population of SIM-welfare on the epidemiological map by describing sociodemographic characteristics, prevalence of ill health and harmful drug use. With this, we aimed to assist public (mental) health policy and welfare-to-work policy to gain insight in this population on which little is known about.

\section{Finding place?}

SIM-welfare were found to be a population of older (mean 49.6), often low educated (53\%), mostly longterm workless men (median 8 years), with considerable health problems: $43 \%$ multiple somatic illnesses, 50\% anxiety and depression; $47 \%$ harmful drug use; and $32 \%$ multiproblems. Also, $14 \%$ of SIM-welfare had experienced a spell of homelessness in their lives. Apparently, a substantial proportion of housed SIM-welfare constitute former rough sleepers who can now fulfil basic needs (roof and income from welfare benefits), but have not found employment.

Judged from how SIM-welfare are stratified on SWI's stairway to work, their labour market position is mostly 
Table 3 Description of sociodemographics, health, drug use and service utilisation compared between single male welfare recipients assessed with a different distance to the labour market and single employed men in Amsterdam

\begin{tabular}{|c|c|c|c|c|c|}
\hline & \multicolumn{4}{|c|}{ Single men receiving welfare benefits in Amsterdam } & \multirow{2}{*}{$\begin{array}{l}\text { Employed single } \\
\text { men in } \\
\text { Amsterdam† } \\
\text { (SIM-work), } n=294\end{array}$} \\
\hline & $\begin{array}{l}\text { Step 1 } \\
\text { 'care', } \\
\mathrm{n}=174\end{array}$ & $\begin{array}{l}\text { Step } 2 \text { 'social } \\
\text { activation', } \\
n=150\end{array}$ & $\begin{array}{l}\text { Steps } 3 \text { and } 4 \\
\text { 're-employment', } \\
n=148\end{array}$ & $\begin{array}{l}\text { Total, } \\
\mathrm{n}=472\end{array}$ & \\
\hline \multicolumn{6}{|l|}{ Sociodemographic variables } \\
\hline Mean age (SD) & $52.2(8.2)^{*}$ & $49.5(10.0)^{*}$ & $46.7(9.6)^{\star}$ & $49.6(9.5)^{\star}$ & $40.3(10.5)$ \\
\hline \multicolumn{6}{|l|}{ Age categories (years) } \\
\hline $23-34$ & $2 \% *$ & $9 \%$ & $16 \%{ }^{*}$ & $9 \% *$ & $33 \%$ \\
\hline $35-44$ & $20 \%$ & $22 \%$ & $21 \% *$ & $21 \% *$ & $33 \%$ \\
\hline $45-54$ & $32 \%$ & $28 \% *$ & $41 \%{ }^{*}$ & $33 \%{ }^{*}$ & $22 \%$ \\
\hline $55-65$ & $47 \%$ & $41 \% *$ & $23 \% *$ & $38 \% \%^{*}$ & $12 \%$ \\
\hline Percentage of low level of education & 53 & 59 & $48^{*}$ & $53^{*}$ & 16 \\
\hline Migrant Dutch $\ddagger$ & 47 & 58 & $68^{*}$ & $57^{\star}$ & $34 \%$ \\
\hline History of homelessness & $16 \%$ & $14 \%$ & $12 \%$ & $14 \%$ & NA \\
\hline Median years of work history & $12^{*}$ & 10 & 10 & 10 & NA \\
\hline \multicolumn{6}{|l|}{ Years of work history in categories } \\
\hline Never worked & $8 \%$ & $12 \%$ & $10 \%$ & $10 \%$ & NA \\
\hline $1-5$ years of work & $19 \%$ & $22 \%$ & $25 \%$ & $22 \%$ & NA \\
\hline $6-15$ years of work & $35 \%$ & $36 \%$ & $37 \%$ & $36 \%$ & NA \\
\hline$>15$ years of work & $39 \%$ & $30 \%$ & $29 \%$ & $33 \%$ & NA \\
\hline $\begin{array}{l}\text { Median years of joblessness (if ever } \\
\text { worked) }\end{array}$ & $11^{*}$ & $9^{*}$ & 4 & 8 & \\
\hline \multicolumn{6}{|l|}{ Years of joblessness in categories } \\
\hline Never worked & $8 \%$ & $12 \%$ & $10 \%$ & $10 \%$ & NA \\
\hline$\leq 3$ years & $13 \%$ & $16 \% *$ & $41 \%$ & $22 \%$ & NA \\
\hline $4-10$ years & $32 \% *$ & $43 \%$ & $36 \%$ & $37 \%$ & NA \\
\hline $11-15$ years & $15 \%$ & $10 \%$ & $7 \%$ & $11 \%$ & NA \\
\hline$>15$ years & $32 \%{ }^{*}$ & $20 \% *$ & $7 \%$ & $20 \%$ & NA \\
\hline \multicolumn{6}{|l|}{ Health indicators } \\
\hline $\begin{array}{l}\text { Percentage of anxiety/depression } \\
(\mathrm{K} 10>19)\end{array}$ & 54 & $54^{*}$ & $40^{*}$ & $50^{*}$ & 26 \\
\hline $\begin{array}{l}\text { Percentage of } 2+\text { chronic somatic } \\
\text { illnesses }\end{array}$ & $54^{*}$ & 39 & $33^{*}$ & $43^{*}$ & 11 \\
\hline $\begin{array}{l}\text { Percentage of excessive drinking } \\
\text { (>21 alc/week) }\end{array}$ & 21 & $25^{*}$ & $12^{*}$ & 19 & 20 \\
\hline $\begin{array}{l}\text { Percentage of } 2+\text { of above health } \\
\text { indicators }\end{array}$ & 42 & $34^{*}$ & $19^{*}$ & $32^{*}$ & 11 \\
\hline $\begin{array}{l}\text { Percentage harmful drinking } \\
\text { (AUDIT >7) }\end{array}$ & 37 & $34^{*}$ & 23 & 32 & NA \\
\hline Percentage of daily cannabis use & 18 & 13 & 18 & 17 & NA \\
\hline Percentage of recent substance abuse & 15 & $15^{*}$ & 6 & 12 & NA \\
\hline Percentage of summary drug use & 54 & 46 & 39 & 47 & NA \\
\hline \multicolumn{6}{|l|}{ Contacts with healthcare in past 12 months } \\
\hline Percentage of GP & $82^{*}$ & $73^{*}$ & $85^{\star}$ & $80^{*}$ & 64 \\
\hline Percentage of Specialist & $65^{\star}$ & 55 & $46^{*}$ & $56^{*}$ & 29 \\
\hline Percentage of Mental health & 24 & 22 & 13 & $20^{*}$ & 10 \\
\hline Percentage of Addiction care & $14^{*}$ & 6 & 6 & $9^{*}$ & 3 \\
\hline Percentage of No care & $4^{\star}$ & 10 & 5 & 6 & 7 \\
\hline
\end{tabular}

one of economic inactivity, as $96 \%$ are judged not readily available to the labour market. The majority $(69 \%)$ are judged to take distant positions from the labour market and are either exempted from vocational progress and subject to case-first care $(37 \%)$ or low threshold participation programmes $(32 \%)$. 
Table 4 Risk of ill health and excessive drinking for (subgroups of) single men on welfare compared against employed single men in Amsterdam; controlled for differences in age, deprivation area, low education and migration history

\begin{tabular}{|c|c|c|c|}
\hline & OR & $(95 \% \mathrm{Cl})$ & p Value \\
\hline \multicolumn{4}{|l|}{ Somatic illness } \\
\hline Employed single men $(n=294)$ & 1 & & \\
\hline Single men on welfare; total group $(n=472)$ & 3.11 & (2.06 to 4.71$)$ & $<0.001$ \\
\hline Single men on welfare; stairway to work step 1 & 4.42 & (2.72 to 7.20$)$ & $<0.001$ \\
\hline Single men on welfare; stairway to work step 2 & 2.60 & (1.56 to 4.35$)$ & $<0.001$ \\
\hline Single men on welfare; stairway to work step 3 & 2.40 & (1.43 to 4.04$)$ & $<0.001$ \\
\hline \multicolumn{4}{|l|}{ Mental illness } \\
\hline Employed single men $(n=294)$ & 1 & & \\
\hline Single men on welfare; total group $(n=472)$ & 4.00 & (2.69 to 5.95$)$ & $<0.001$ \\
\hline Single men on welfare; stairway to work step 1 & 5.50 & (3.36 to 9.01 ) & $<0.001$ \\
\hline Single men on welfare; stairway to work step 2 & 5.29 & (3.18 to 8.79$)$ & $<0.001$ \\
\hline Single men on welfare; stairway to work step 3 & 2.46 & (1.51 to 4.01$)$ & $<0.001$ \\
\hline \multicolumn{4}{|l|}{ Excessive drinking } \\
\hline Employed single men $(n=294)$ & 1 & & \\
\hline Single men on welfare; total group $(n=472)$ & 0.89 & (0.57 to 1.40$)$ & 0.622 \\
\hline Single men on welfare; stairway to work step 1 & 0.83 & (0.47 to 1.46$)$ & 0.515 \\
\hline Single men on welfare; stairway to work step 2 & 1.42 & (0.81 to 2.48$)$ & 0.227 \\
\hline Single men on welfare; stairway to work step 3 & 0.55 & (0.28 to 1.08$)$ & 0.083 \\
\hline \multicolumn{4}{|l|}{ Multiproblem } \\
\hline Employed single men $(n=294)$ & 1 & & \\
\hline Single men on welfare; total group $(n=472)$ & 3.80 & (2.40 to 6.03$)$ & $<0.001$ \\
\hline Single men on welfare; stairway to work step 1 & 5.66 & (3.30 to 9.69$)$ & $<0.001$ \\
\hline Single men on welfare; stairway to work step 2 & 4.50 & (2.59 to 7.82$)$ & $<0.001$ \\
\hline Single men on welfare; stairway to work step 3 & 2.04 & (1.13 to 3.69$)$ & 0.018 \\
\hline
\end{tabular}

To gain insight in the degree and nature of health disadvantages and disadvantaged healthcare utilisation for health needs, we compared SIM on welfare with SIM-work. In addition, we studied whether subgroups assessed with a larger distance to the labour market were also more vulnerable from a public health perspective. If so, the classification used to differentiate reintegration policy might also be used to differentiate public health inventions.

\section{Disadvantaged health?}

As expected, health disadvantages among SIM-welfare compared with SIM-work are substantial and are in line with mechanisms of causation and health-selection

Table 5 Use of health services, contrasted between SIM-welfare and SIM-work (model 1) and between subgroups of SIM-welfare assessed with a different distance to the labour market (model 2), controlled for differences in relevant health needs and sociodemographic background variables*

\begin{tabular}{|c|c|c|c|c|c|}
\hline \multirow[b]{2}{*}{ Binary logistic regression models } & \multicolumn{5}{|c|}{ Contact with healthcare services in past 12 months (1=yes) } \\
\hline & $\begin{array}{l}\text { GP } \\
\text { OR }(95 \% \mathrm{CI}) \\
\end{array}$ & $\begin{array}{l}\text { Specialist care } \\
\text { OR }(95 \% \mathrm{Cl})\end{array}$ & $\begin{array}{l}\text { Mental healthcare } \\
\text { OR }(95 \% \mathrm{Cl})\end{array}$ & $\begin{array}{l}\text { Addiction care } \\
\text { OR }(95 \% \mathrm{Cl})\end{array}$ & $\begin{array}{l}\text { No care } \\
\text { OR }(95 \% \mathrm{Cl})\end{array}$ \\
\hline \multicolumn{6}{|c|}{ Model 1: comparing SIM-welfare to SIM-work† } \\
\hline SIM-welfare & ns 1.0 & $1.9(1.3$ to 2.8$)$ & $2.9(1.6$ to 5.3$)$ & 5.6 (1.6 to 20.3$)$ & ns 1.3 \\
\hline SIM-work & 1 & 1 & 1 & 1 & 1 \\
\hline \multicolumn{6}{|c|}{$\begin{array}{l}\text { Model 2: comparing between subgroups of SIM-welfaref } \\
\text { Distance to labour market }\end{array}$} \\
\hline Step 1 'care' & ns 0.8 & $1.8(1.0$ to 3.0$)$ & $2.3(1.2$ to 4.7$)$ & ns 3.2 & ns 1.0 \\
\hline Step 2 'social activation' & ns 0.5 & ns 1.5 & $2.0(1.0$ to 4.1$)$ & ns 1.6 & ns 2.6 \\
\hline Step 3 and 4 're-employment' & 1 & 1 & 1 & 1 & 1 \\
\hline \multicolumn{6}{|c|}{$\begin{array}{l}\text { *All analyses were conducted with control variables: age, education, deprivation area and migration history. } \\
\text { †Relevant health variables controlled for in model } 1: \text { GP: mental illness, somatic illness and excessive drinking; Specialist care: somatic } \\
\text { illness; Mental healthcare: mental illness; Addiction care: excessive drinking; No care: mental illness, somatic illness and excessive drinking. } \\
\text { †Relevant health variables controlled for in model } 2 \text { : same as model } 1 \text { except instead of excessive drinking, harmful drinking, daily cannabis } \\
\text { use and recent substance abuse were entered as control variables. } \\
\text { Bold typeface indicates significance at } p<0.05 \text { level. } \\
\text { ns: association is non-significant ( } p>0.05) \text {. } \\
\text { GP, general practitioner; SIM-welfare, single male welfare recipients; SIM-work, single employed men. }\end{array}$} \\
\hline
\end{tabular}


mostly supported by findings from studies ${ }^{18-20}$ in which workers are compared with the unemployed, especially for mental health.

For harmful drug use, comparison with SIM-work was limited to differences in the prevalence of excessive drinking, which were insignificant. More studies report small or insignificant differences in excessive or hazardous drinking between employed and unemployed populations, but a higher prevalence for alcohol dependence, illicit drug use and cannabis use is generally found. ${ }^{21}$ Adequate reference data on drug use indicators among SIM-work are needed to further elaborate on this.

\section{Disadvantaged service use?}

No evidence was found for a higher proportion of unmet needs among SIM-welfare compared with SIM-work. On the contrary, controlled for (relevant) health problems and background variables, SIM-welfare were found more likely to have healthcare contacts than SIM-work.

Since we did not correct for severity of health problems, the finding might reflect that health problems among SIM-welfare are more severe. Other studies, ${ }^{31-33}$ with correction for severity, also showed higher service use for jobless populations, compared with the employed. As an explanation for higher service use, Honkonen et $a l^{31}$ point to the extra time jobless individuals have and the strong linkages between healthcare and the welfare agency. These supportive findings make it unlikely that controlling for severity of symptoms would have yielded opposite results. In terms of unmet needs, SIM-welfare seem no more vulnerable than SIM-work.

Not accessing healthcare, while this is needed from a health professionals' perspective, might still be one of the explanations why SIM are over-represented among clients of PMHC. Future research comparing, for instance, SIM with non-SIM or SIM against single woman might shed more light on this.

\section{Useful subgroups?}

Stratifying SIM-welfare along SWI's stairway to work proved useful as it reflected not only differences in age and duration of joblessness, but also significant health differences if controlled for these background variables. As such, the classification seems to do what it is supposed to do: it takes into account health-related participation restrictions. As such, it provides information about (1) what kind of reintegration policy is (locally) associated with what kind of health problems and (2) what kind of health problems can be 'found' and targeted within each of this (registered) categories. This information is especially relevant not only for local policy in Amsterdam, but also for other Dutch cities with comparable classifications for welfare recipients.

It was found that one step up from the 'care' category to the 'social activation' category was mainly associated with better somatic health. Again one step closer to the labour market, to the 're-employment' category of increased pressure and opportunity to participate,
SIM-welfare showed less mental health problems, less drug use and less combined health problems but were still worse of on all health indicators compared with SIM-work.

Apparently, especially adding somatic illnesses to the equation of disadvantaged human capital and other health problems is most likely to put clients in a position in which vocational improvement is of secondary importance and the main priority is to improve/stabilise health (financed from other funds). It is hard to interpret this finding as possibly somatic illnesses are most likely to be picked up and assessed as a major personal barrier by SWI, while, in fact, mental illness might more severely restrict labour market participation. It does, however, implicate that, for this long-term jobless population of SIMwelfare, somatic health problems pose a more important barrier than what the unemployment research suggests. Also, it raises the question whether this population of welfare clients differs much from the population of people receiving disability benefits.

\section{Generalising findings}

In this study, extra effort was put into creating a representative sample of a population which is hard to reach. On average, clients not reached were visited at least six times at their homes and contacted 20 times by telephone. This led to a $26 \%$ response rate, which demonstrates that this specific group would probably be missed in general (health) surveys.

Although particular subgroups might be underrepresented in the sample, the non-response analysis showed accurate representation on compared variable and authors are unaware of studies to date with better response rates among this particular group, voluntarily interviewed outside the welfare setting.

Generalisability of findings across time and space is limited, but seems accurate for other urban settings with mixed ethnicities, healthcare with low financial barriers and universal entitlements to welfare benefits enabling to fulfil basic needs.

\section{Conclusion and policy implications}

The findings confirm that SIM-welfare are a vulnerable group with disadvantaged human capital and health problems. Transitions from welfare towards work among SIM-welfare apply to further rehabilitation of a substantial group of former rough sleepers towards work.

The findings also underline the importance of a rehabilitation perspective on welfare-towards-work policy, taking health barriers into account. Since relative vulnerability in terms of unmet needs was not found among welfare clients, promoting access of healthcare seems no more a priority among SIM-welfare than among single male workers.

SWI's 'stairway to work' shows that clients can be stratified along dimensions reflecting health needs (ie, barriers) and traditional human capital indicators. With these kinds of classifications, it seems possible to stratify 
clients and expose them to programmes in which a mix of health promotion, labour market activation and care is balanced towards adequately improving vocational progress, health and possibly preventing homelessness. In Amsterdam, the perspectives of 'care' and vocational progress hardly seem to mix. Adding vocational perspectives to case-first-care and rehabilitation care perspectives to re-employment practices could improve health and re-employment outcomes. In order to accomplish this, 'care' and 'vocational training' should probably cooperate within a shared financing structure integrating costs and benefits.

\section{Author affiliations}

${ }^{1}$ Academic Collaborative Urban Social Exclusion Research (USER-G4), Public Health Service, Department of Epidemiology and Health Promotion,

Amsterdam, The Netherlands

${ }^{2}$ Public Health Service, Department of Epidemiology and Health Promotion, Amsterdam, The Netherlands

${ }^{3} \mathrm{VU}$ Medical Center, Department of Psychiatry, Amsterdam, The Netherlands

Acknowledgements The authors thank the peer interviewers for their effort and perseverance during data collection. The Service for Work and Income, Amsterdam Statistics and Radar Advies are thanked for their cooperation.

Contributors TCK contributed to the study design, coordinated data collection, helped train peer interviewers, performed analysis and wrote the article. MASdW initiated the research, contributed to study design, analysis and commented on the article. SC contributed to the study design and commented on the article. ATFB contributed to the study design and made important contributions to the article.

Funding ZONmw, Public health service Amsterdam, Municipal Service for Work \& Income Amsterdam, ACHMEA healthcare insurance.

Competing interests None.

Ethics approval The study was presented to the Medical Ethics Committee (METc) at VU University Medical Centre.

Provenance and peer review Not commissioned; externally peer reviewed.

Data sharing statement Used dataset for SIM-welfare can be accessed online for use as reference data.

Open Access This is an Open Access article distributed in accordance with the Creative Commons Attribution Non Commercial (CC BY-NC 3.0) license, which permits others to distribute, remix, adapt, build upon this work noncommercially, and license their derivative works on different terms, provided the original work is properly cited and the use is non-commercial. See: http:// creativecommons.org/licenses/by-nc/3.0/

\section{REFERENCES}

1. Van Laere I, De Wit M, Klazinga N. Shelter-based convalescence for homeless adults in Amsterdam: a descriptive study. BMC Health Serv Res 2009;1:1-8.

2. Nusselder WJ, Slockers MT, Krol L, et al. Mortality and life expectancy in homeless men and women in Rotterdam: 2001-2010. PLOS ONE 2013;8:e73979.

3. Nielsen SF, Hjorthøj CR, Erlangsen A, et al. Psychiatric disorders and mortality among people in homeless shelters in Denmark: a nationwide register-based cohort study. Lancet 2011;377:2205-14.
4. Fazel S, Khosla V, Doll H, et al. The prevalence of mental disorders among the homeless in Western countries: systematic review and meta regression analysis. PLoS Med 2008;12:e225.

5. Hwang SW. Homelessness and health. CMAJ 2001;164:229-33.

6. Fitzpatrick S, Stephens M. An international review of homelessness and social housing policy. London: Department for Communities and Local Government, 2007:17.

7. Stephens M, Fitzpatrick S, Elsinga M, et al. Study on housing exclusion: welfare policies, housing provision and labour markets. Brussels: European Commission, Directorate-General for Employment, Social Affairs and Equal Opportunities, 2010:197.

8. European Union. http://ec.europa.eu/europe2020/pdf/themes/25 poverty_and_social_inclusion.pdf (accessed 17 Jan 2013)

9. Buster MCA, Hensen M, De Wit M, et al. Feitelijk dakloos in de G4. GGD Amsterdam, GGD Rotterdam-Rijnmond, GGD Den Haag, GG\&GD Utrecht, 2012.

10. Public Health Service Amsterdam: aggregated Public Mental Health database 2012

11. Nationale Raad voor de Volksgezondheid. Advies openbare geestelijke gezondheidszorg. Den Haag: NRV, 1991.

12. Statistics Netherlands; Statline database: http://statline.cbs.nl/ statweb/?LA=en (accessed 20 Jun 2013).

13. Jahoda M. Employment and unemployment: a social-psychological analysis. Cambridge: Cambridge Univeristy Press, 1982.

14. Warr P. Work, unemployment, and mental health. Oxford: Clarendon Press, 1987

15. Waddell G, Burton K. Is working good for your health and well-being? Cardiff \& Huddersfield: Cardiff University \& University of Huddersfield, 2006.

16. Perkins D. Improving employment participation for welfare recipients facing personal barriers. Soc Policy Society 2008;7:13-26.

17. Koen J, Klehe UC, Vianen A van. Competentieontwikkeling \& Re-integreerbaarheid van DWI Klanten. Amsterdam: UvA, 2008.

18. McKee Ryan F, Song Z, Wanberg CR, et al. Psychological and physical well-being during unemployment: a meta-analytic study. $J$ Appl Psychol 2009;90:53-75.

19. Paul KI, Moser K. Unemployment impairs mental health: meta-analyses. J Vocat Behav 2009;74:254-82.

20. Wanberg CR. The individual experience of unemployment. Annu Rev Psychol 2012;63:369-96.

21. Henkel D. Unemployment and substance use: a review of the literature (1990-2010). Curr Drug Abuse Rev 2011;4:4-27.

22. Dijkshoorn H, Dijk TK v, Janssen AP. Zo gezond is Amsterdam!: eindrapport Amsterdamse Gezondheidsmonitor 2008. Amsterdam: GGD Amsterdam, 2009.

23. Municipal Personal Records Database Amsterdam; 2010.

24. Kessler RC, Barker PR, Colpe LJ, et al. Screening for serious mental illness in the general population. Arch Gen Psychiatry 2003;60:184-9.

25. Andrews $\mathrm{G}$, Slade T. Interpreting scores on the Kessler Psychological Distress Scale (K10). Aust N Z J Public Health 2001;25:494-7.

26. Victorian Government. Victorian population health survey 2001 selected findings. Melbourne: Department of Human Services, 2002

27. Donker T, Comijs, Cuijpers $\mathrm{P}$, et al. The validity of the Dutch K10 and extended K10 screening scales for depressive and anxiety disorders. Psychiatry Res 2010;1:45-50.

28. Babor TF, Higgins-Biddle JC, Saunders JB, et al. AUDIT: the Alcohol Use Disorders Identification Test: guidelines for use in primary care. Geneva: World Health Organization, 2001.

29. Conigrave KM, Hall WD, Saunders JB. The AUDIT questionnaire: choosing a cut-off score: Alcohol Use Disorders Identification Test. Addiction 1995;90:1349-56.

30. Kish L. Weighting for Unequal $P_{i}$. J Official Stat 1992;8:183-200.

31. Honkonen T, Virtanen M, Ahola K, et al. Employment status, mental disorders and service use in the working age population. Scand $J$ Work Environ Health 2007;33:29-36.

32. Bijl RV, Ravelli A. Psychiatric morbidity, service use, and need for care in the general population: results of the Netherlands Mental Health Survey and Incidence Study. Am J Public Health 2000;90:602-7.

33. Kraut A, Mustard C, Walld R, et al. Unemployment and health care utilization. Scand J Work Environ Health 2000;26:169-77. 